\title{
Improvement of the noradrenergic symptom cluster following treatment with milnacipran
}

This article was published in the following Dove Press journal:

Neuropsychiatric Disease and Treatment

3I May 20II

Number of times this article has been viewed

\author{
Siegfried Kasper \\ Diana Meshkat \\ Alexandra Kutzelnigg \\ Department of Psychiatry and \\ Psychotherapy, Medical University \\ of Vienna, Vienna, Austria
}

Correspondence: Siegfried Kasper Department of Psychiatry and Psychotherapy, Medical University Vienna, AKH, Währinger Gürtel I8-20, A-1090 Vienna, Austria

Tel +43 | 404003568

Fax +43 I 404003099

Email sci-biolpsy@meduniwien.ac.at
Abstract: Depression has a major impact on social functioning. Decreased concentration, mental and physical slowing, loss of energy, lassitude, tiredness, and reduced self-care are all symptoms related to reduced noradrenergic activity. Depressed mood; loss of interest or pleasure; sleep disturbances; and feelings of worthlessness, pessimism, and anxiety are related to reduced activity of both serotonergic and noradrenergic neurotransmission. The importance of noradrenergic neurotransmission in social functioning is supported by studies with the specific norepinephrine reuptake inhibitor reboxetine. In healthy volunteers, reboxetine increases cooperative social behavior and social drive. A placebo-controlled study in depressed patients comparing reboxetine with the selective serotonin reuptake inhibitor (SSRI) fluoxetine showed significantly greater improvement in social adaptation with reboxetine. Two recent studies have examined the effect of the serotonin and norepinephrine reuptake inhibitor milnacipran on social adaptation. A study in depressed patients found that at the end of 8 weeks of treatment with milnacipran, $42.2 \%$ patients were in remission on the Social Adaptation Self-evaluation Scale (SASS). Another study in depressed workers or homemakers found that mean depression scores were significantly reduced after 2 weeks, whereas the SASS scores were significantly improved after 4 weeks. A preliminary study comparing depressed patients treated with milnacipran or the SSRI paroxetine showed that milnacipran treatment resulted in a greater number of patients in social remission. The available data thus suggest that milnacipran may improve social functioning, with a possibly greater effect than the SSRI paroxetine. These preliminary data suggest further evaluation of social dysfunction and its treatment outcome in future trials of milnacipran.

Keywords: social functioning, Social Adaptation Self-evaluation Scale (SASS), depression, noradrenergic neurotransmission, serotonin and norepinephrine reuptake inhibitors (SNRIs), milnacipran

\section{Introduction}

The widespread disturbances of monoamine neurotransmission that occur in depression are probably fundamental to its pathophysiology. ${ }^{1,2}$ More specifically, a deficiency in serotonin (5-HT), norepinephrine (NE), and possibly dopamine (DA) neurotransmission has been suggested. ${ }^{3,4}$ A relationship exists between the different neurotransmitter deficits and the symptoms of major depression. ${ }^{5}$ Depressed mood; loss of interest or pleasure; sleep disturbances; and feeling of worthlessness, pessimism, and anxiety are symptoms related to changes in both 5-HT and NE neurotransmission. ${ }^{5,6}$ Agitation, loss of appetite, decreased libido, suicidal ideation, aggressive behavior (verbal or physical), and irritability are symptoms related principally to the dysfunction of 5-HT 
neurotransmission., ${ }^{5,6} \mathrm{DA}$ is important in the regulation of drive. ${ }^{7,8}$ Reduced noradrenergic activity is responsible for decreased concentration, mental and physical slowing, loss of energy, lassitude, tiredness, and reduced self-care. ${ }^{5,6}$

\section{Noradrenergic symptom cluster and social dysfunction}

The symptoms that are thought to be principally due to a deficit in noradrenergic transmission, the so-called noradrenergic symptom cluster, are those that result in social dysfunction (Figure 1). "Social dysfunction" is a collective term used to describe a variety of emotional problems experienced in social situations. It frequently leads to family disruption and social isolation. In the workplace it can lead to absenteeism and "presenteeism" (a term used to describe the lost productivity a worker experiences when he or she is able to attend work but is not performing optimally. ${ }^{9}$ Depression has a major negative impact on social functioning, ${ }^{10-14}$ which is possibly one of the most important factors affecting quality of life in depressed patients.

In the International Classification of Diseases, 10th Revision (ICD-10) and Diagnostic and Statistical Manual of Mental Disorders, 4th Edition (DSM-IV) diagnostic criteria of major depression, the item "lack of interests or pleasure" only partly covers the concept of decreased social ability. However, in addition to the simple presence of certain symptoms, DSM-IV requires that the symptoms should cause significant distress or impairment in social, occupational, or other important areas of functioning. ${ }^{15}$

\section{Improvement of social dysfunction during antidepressant treatment}

Increasingly, the enhancement of social functioning is considered to be an important therapeutic target in the treatment of depression. ${ }^{15,16}$ Full recovery from depression thus

\section{Noradrenergic symptom cluster}

\section{Social dysfunction}

Decreased concentration
Retardation
Loss of energy
Lassitude
Tiredness
Reduced self-care

Figure I The noradrenergic symptom cluster and social dysfunction. The components of the noradrenergic symptom cluster are closely linked to social dysfunction. "Presenteeism" is a term used to describe the lost productivity a worker experiences when he or she is able to attend work but is not performing optimally. requires not only the resolution of classical symptoms but also an improvement in the interaction of the individual with his or her environment. ${ }^{10,11,13}$ The ability to improve social functioning should legitimately influence the choice of antidepressant therapy. ${ }^{12}$

The measurement of social adaptation should therefore be an integral part of the assessment of the outcome of depressive episodes. A number of instruments have been developed to measure social functioning, each with certain advantages and disadvantages. ${ }^{17}$ Although several self- or clinician-evaluated social adjustment scales are available, they are frequently complex and time consuming, and their conceptual background is often poorly defined. ${ }^{18-20}$ The three most frequently used instruments for measuring social functioning are the 36-item Short-Form Health Survey, ${ }^{21}$ the Social Adjustment Scale Self-report, ${ }^{22}$ and the more recently developed Social Adaptation Self-evaluation Scale (SASS). ${ }^{18}$ It has been suggested ${ }^{17}$ that the SASS might be the most appropriate for studies exploring hypotheses about mechanisms involved in social dysfunction.

The importance of NE neurotransmission in social functioning is supported by studies using the specific NE reuptake inhibitor reboxetine. The effects of reboxetine have been studied in healthy volunteers using a stranger-dyadic social interaction paradigm and cooperative game situations, ${ }^{22-24}$ where it was found to increase cooperative social behavior and social drive, making participants more self-confident and assertive. In contrast, the selective serotonin reuptake inhibitor (SSRI) citalopram had significantly less effect on cooperative behavior. ${ }^{22}$

Because depression causes extensive social dysfunction, antidepressant treatment would be expected to lead to improved social functioning. An early study ${ }^{25}$ found that social and interpersonal maladjustments occurring in depressed women improved with antidepressant treatment during 8-month follow-up. The considerable improvement in social adjustment, however, occurred more slowly than for other symptoms. Symptomatic relapse was accompanied by rapid social worsening. ${ }^{25}$

The first double-blind, placebo-controlled study to use the SASS showed that 8 weeks of treatment with reboxetine $(8 \mathrm{mg} / \mathrm{d})$ resulted in a significantly greater improvement in social functioning compared with patients treated with the SSRI fluoxetine $(20 \mathrm{mg} / \mathrm{d})$ or with placebo (Figure 2). ${ }^{26,27}$ Another study ${ }^{28}$ comparing the effects of reboxetine $(8-10 \mathrm{mg} / \mathrm{d})$ and fluoxetine $(20-40 \mathrm{mg} / \mathrm{d})$ over 8 weeks found that both antidepressants improved the scores on the Hamilton Depression Rating Scale (HDRS) to a similar 


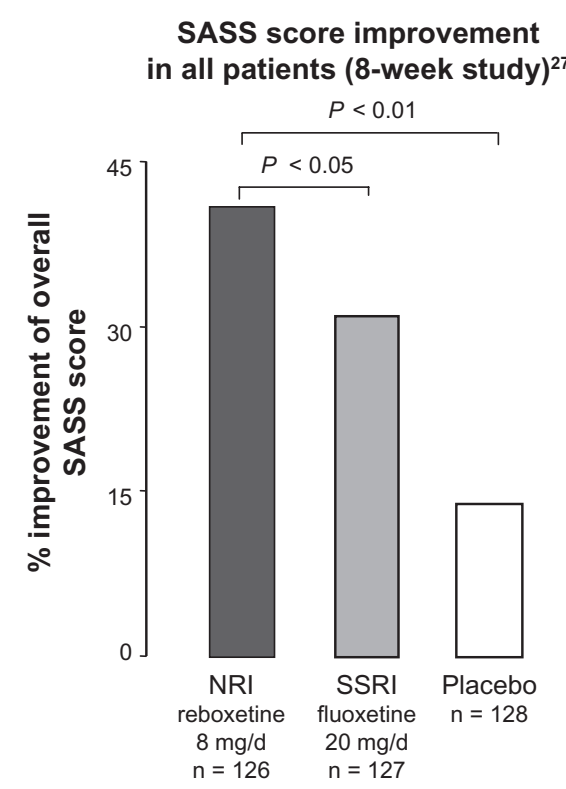

\section{SASS score improvement in patients in remission (4-week study) ${ }^{28}$}

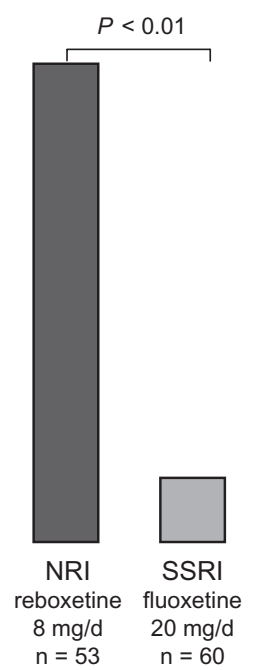

Figure 2 Improvement in Social Adaptation Self-evaluation Scale (SASS) score during antidepressant therapy. Drawn from data in references 27 and 28.

Abbreviations: NRI, norepinephrine reuptake inhibitor; SSRI, selective serotonin reuptake inhibitor.

extent. In patients who achieved remission from their depressive symptoms, however, social dysfunction was improved to a significantly greater extent by patients taking reboxetine compared with fluoxetine (Figure 2).

These studies suggest that antidepressants with an important noradrenergic component, such as reboxetine, may be particularly effective in improving social functioning. ${ }^{29}$ If improved social adaptation is related to increased NE activity, then serotonin and norepinephrine reuptake inhibitors (SNRIs) should be particularly effective in reducing social dysfunction in depressed patients.

There have been relatively few studies of SNRIs investigating their effects on social adaptation. A small study ${ }^{30}$ that compared treatment of depressed patients with venlafaxine and amitriptyline found the two drugs to be equally effective in relieving depressive symptoms. Venlafaxine-treated patients showed a significantly greater improvement in social adjustment. An open-label case study of five patients with treatment-resistant severe depression ${ }^{31}$ found that treatment with high-dose (450-600 mg/d) venlafaxine resulted in an improvement in depressive symptoms $(>50 \%$ decrease in baseline HDRS scores) in four patients. Social adjustment scores of two of these patients were normalized by the end of the study. An open-label study of 26 patients suffering from seasonal affective disorder (SAD) ${ }^{32}$ treated with duloxetine $(60-120 \mathrm{mg} / \mathrm{d})$ for 8 weeks showed that both SAD and social adaptation were improved. The studies with milnacipran are discussed at the end of the next section.

\section{Milnacipran: the most noradrenergic SNRI}

Of the four SNRIs currently available, milnacipran is the most noradrenergic in terms of its selectivity for the inhibition of the reuptake of NE and 5-HT (Figure 3). ${ }^{33,34}$ There is neurochemical and neurophysiological evidence that milnacipran acts by increasing NE neurotransmission. A study investigating the influence of NE transporter polymorphism (NET-T182C polymorphism) on the antidepressant effect of milnacipran ${ }^{35}$ found a significant difference $(P<0.03)$ in response, depending on the genotype of the patients ( $\mathrm{T} / \mathrm{T} 76.7 \%$ responders; T/C 57.8\% responders; C/C 20\% responders). Similarly, antidepressant response with milnacipran was sensitive to NET-G1287A polymorphism, with the A/A genotype being associated with a slower onset of therapeutic response. ${ }^{35}$

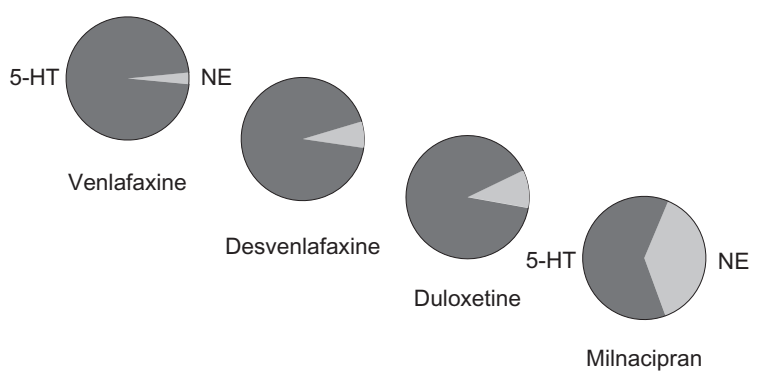

Figure 3 Visual representation of the selectivity for serotonin (5-HT) and norepinephrine (NE) transporter in vitro. The light gray segments represent the relative affinity for the $5-\mathrm{HT}$ transporter, and the dark gray segments represent the relative affinity for the NE transporter.

Calculated from data in reference 33 . 
In contrast, there was no influence of 5-HTT polymorphisms on the antidepressant response to milnacipran..$^{35}$ These results suggest that the effect of milnacipran on the NE transporter is fundamental to its action.

\section{The effects of milnacipran on the noradrenergic symptom cluster Concentration}

The effect of milnacipran has been specifically studied on certain symptoms of the noradrenergic symptom cluster. The critical flicker fusion (CFF) task ${ }^{38}$ evaluates the integrative capacity of the brain and the ability to discriminate discrete quanta of sensory information. The CFF is sensitive to psychoactive drugs, and a decrease in CFF threshold indicates decreased cognitive capacity. In a study of elderly ( $>65$ years) healthy volunteers in whom amitriptyline (50 mg/d for 3 days) significantly decreased CFF, milnacipran ( $75 \mathrm{mg} / \mathrm{d}$ for 3 days) caused a small but significant increase in CFF, indicating a small enhancement of cognitive capacity. ${ }^{39}$

\section{Retardation}

The HDRS defines "retardation" in item 8 as slowness of thought and speech, impaired ability to concentrate, and decreased motor activity, and rates it on a $0-4$ scale. A subanalysis of data from a study comparing milnacipran $(100 \mathrm{mg} / \mathrm{d})$ with paroxetine $(20 \mathrm{mg} / \mathrm{d})^{40}$ examined item 8 of the HDRS in comparison with response on the Clinical Global Improvement (CGI) scale. Patients with low levels of retardation (score 0 or 1 ) had similar response rates on milnacipran and paroxetine. Patients with high levels of retardation (score 3 or 4), however, responded significantly better to milnacipran than to paroxetine (Figure 4).

\section{Tiredness}

Milnacipran has not been investigated extensively in sleep disorders, but in various studies milnacipran has been noted to improve disturbed sleep patterns by decreasing sleep latency and nocturnal awakenings and increasing the latency of rapid eye movement sleep. ${ }^{39-42}$ This improvement in sleep is likely to go some way to improving tiredness.

\section{The effects of milnacipran on social dysfunction}

Two recent studies have examined the effect of milnacipran on social adaptation as measured by the SASS. Both

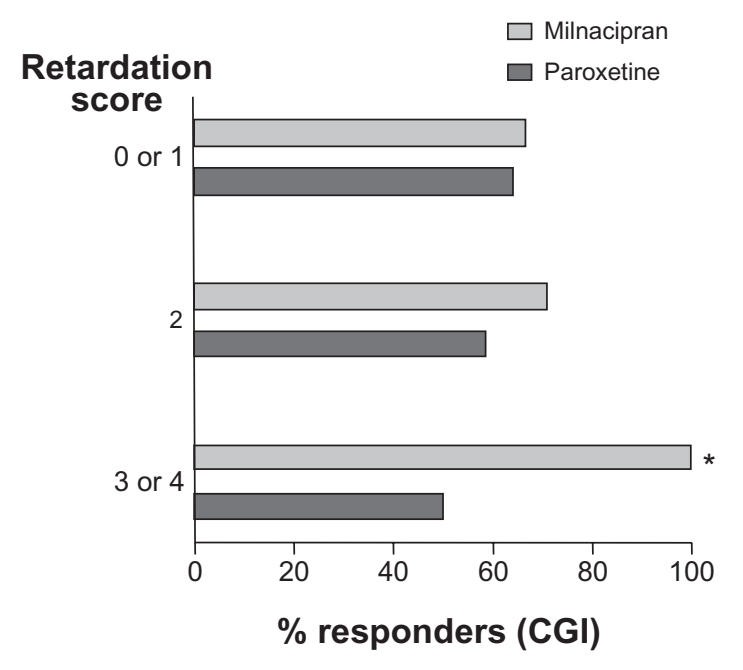

Figure 4 Antidepressant response and the degree of psychomotor retardation. Retardation score is the score on item 8 of the Hamilton Depression Rating Scale. Drawn from data in reference 38.

Note: $* P<0.05$ compared with paroxetine-treated patients with retardation scores of 3 or 4 .

Abbreviation: CGI, Clinical Global Improvement.

have been published exclusively in Japanese but have been presented and discussed in detail in a recent review. ${ }^{43}$

In one study, ${ }^{44}$ milnacipran was administered at $50 \mathrm{mg} / \mathrm{d}$, increasing to $100 \mathrm{mg} / \mathrm{d}$ (mean final dose $83.7 \mathrm{mg} / \mathrm{d}$ ) to 45 patients with major depressive disorder for 8 weeks. Significant improvement in the classical symptoms of depression, as measured by HDRS and Beck Depression Inventory (BDI), was observed after 2 weeks, and significant improvement of social dysfunction (SASS) after 4 weeks (Figure 5). After 8 weeks of treatment, $51.1 \%$ patients were in remission for depression (HDRS $<7$ ) and $42.2 \%$ for social dysfunction (SASS > 35). Nonresponders on the HDRS had no significant improvement in their SASS score at endpoint. There was a significant negative correlation $(P<0.01)$ between the reduction in HDRS score from baseline to endpoint and the increase in SASS score from baseline to endpoint.

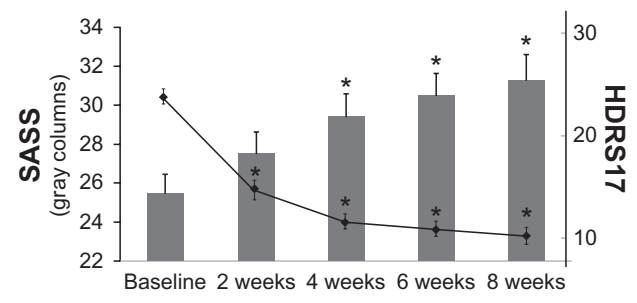

Figure 5 Evolution of depression and social function during milnacipran treatment. Depression ratings (black lozenges and line) are the mean Hamilton Depression Rating Scale (HDRS 17 ) scores ( \pm standard error of the mean). Social function ratings are the mean Social Adaptation Self-evaluation Scale (SASS) scores ( \pm standard error of the mean).

Drawn from data in reference 44.

Note: $* P<0.01$ compared with respective baseline values; $\mathrm{n}=101$ used for intention-to-treat analysis. 
The second study ${ }^{45}$ included 113 patients, employees, or homemakers with major depressive episodes. Milnacipran was administered at $25-50 \mathrm{mg} / \mathrm{d}$, increasing to $100 \mathrm{mg} / \mathrm{d}$ by 2 weeks, and then continuing at this dose for 8 weeks (average final dose $85.4 \mathrm{mg} / \mathrm{d}$ ). Mean HDRS and Zung Self-rating Depression Scale (SDS) scores were significantly reduced $(P<0.01)$ from 2 weeks, whereas the SASS was only significantly increased $(P<0.01)$ from 4 weeks. At endpoint, $67.4 \%$ patients were classified as responders ( $\geq 50 \%$ reduction of baseline HDRS), and $43.0 \%$ were in remission (HDRS $\leq 7$ ); 33.3\% patients had remission on SASS ( $\geq 35$ points). There was a significant negative correlation between $\triangle$ SASS (baseline to endpoint difference) and $\triangle$ HDRS $(-0.39 P<0.01)$, although the correlation was considerably weaker than between the two depression scales ( $\triangle$ HDRS and $\triangle$ SDS; $0.74 P<0.01$ ).

Both studies showed significant improvement on the SASS scale from 4 weeks of treatment, whereas a significant improvement on depression scales occurred by 2 weeks. Both studies reported a significant negative correlation between changes in the SASS and changes in the HDRS. This correlation was, however, weaker than that between two depression rating scales. Globally, these data suggest that improvement in social function, as measured by the SASS, may be more difficult and slower to achieve than improvement in classical depressive symptoms.

A recent review of the effect of SNRIs on social function ${ }^{43}$ mentions an unpublished study that compares the improvement of social function in depressed patients treated with milnacipran (mean dose $83 \mathrm{mg} / \mathrm{d}$ ) and paroxetine (mean dose $35 \mathrm{mg} / \mathrm{d}$ ). Milnacipran treatment resulted in a greater number of patients with social remission than treatment with paroxetine.

\section{Conclusion}

The symptoms that constitute the noradrenergic symptom cluster are those that play an important role in social dysfunction. There is a suggestion that antidepressants activating NE neurotransmission may improve social functioning more rapidly and/or to a greater extent than those acting exclusively on 5-HT function..$^{43}$ The efficacy of reboxetine in the recovery of social function compared with SSRIs is compatible with the importance of noradrenergic deficit in social dysfunction. If this is indeed true, SNRIs would also be expected to be particularly effective in improving social functioning.

Milnacipran is the most noradrenergic SNRI in terms of its selectivity for the NE transporter and 5-HT transporter.
It has been shown to have positive effects on concentration and retardation. This latter effect has been shown to be significantly greater than with paroxetine. Among the SNRIs, milnacipran might therefore be expected to be particularly effective in reducing social dysfunction associated with depression. Evidence, which is still incomplete, suggests that milnacipran may improve social function in depressed patients. Although the effects on depressive symptoms and social dysfunction are correlated, improvement in social function appears to have a slower time course than improvement of other depressive symptoms.

The studies that are currently available are all small, and many of them are not comparative. This is a clear limitation of support for the hypothesis. Although there is a first indication that milnacipran may possibly produce a greater improvement of social function than paroxetine, the question is still open. Clearly, the studies need to be replicated in a controlled and comparative environment. In addition, the interesting question of the potential positive interaction between psychotherapy and pharmacotherapy in the improvement of social function needs to be addressed.

Social dysfunction is one of the most important factors affecting quality of life of depressed patients, and it is possibly of even greater importance in the treatment of elderly patients suffering from major depression. For the patient to recover fully from the effects of depression, it is important to have not only full and sustained relief from the classical symptoms of depression but also a complete recovery of the ability to interact with friends and other individuals in the family and work environment. The enhancement of social functioning should thus be considered a major therapeutic goal in the management of depression.

\section{Acknowledgment}

The author would like to thank Dr Mike Briley for his editorial help in the preparation of this manuscript.

\section{Disclosure}

Dr Kasper has received grant/research support from Eli Lilly, Lundbeck, Bristol-Myers Squibb, GlaxoSmithKline, Organon, Sepracor, and Servier; has served as a consultant or on advisory boards for AstraZeneca, Bristol-Myers Squibb, GlaxoSmithKline, Eli Lilly, Lundbeck, Pfizer, Organon, Schwabe, Sepracor, Servier, Janssen, and Novartis; and has served on speakers' bureaus for AstraZeneca, Eli Lily, Lundbeck, Schwabe, Sepracor, Servier, Pierre Fabre, and Janssen. Dr Kutzelnigg has received travel grants from Eli Lilly and Affiris AG and payment for lectures including 
service on speakers' bureaus from Eli Lilly, Novartis, and Affiris AG. Dr Meshkat received a travel grant from Affiris.

\section{References}

1. Charney DS. Monoamine dysfunction and the pathophysiology and treatment of depression. J Clin Psychiatry. 1998;59(Suppl 14): $11-14$.

2. Leonard BE. Noradrenaline in basic models of depression. Eur Neuropsychopharmacol. 1997;7(Suppl 1):S11-S16.

3. Bymaster FP, McNamara RK, Tran PV. New approaches to developing antidepressants by enhancing monoaminergic neurotransmission. Expert Opin Investig Drugs. 2003;12:531-543.

4. Klimek V, Schenck JE, Han H, Stockmeier CA, Ordway GA. Dopaminergic abnormalities in amygdaloid nuclei in major depression: a postmortem study. Biol Psychiatry. 2002;52:740-748.

5. Nutt DJ. Relationship of neurotransmitters to the symptoms of major depressive disorder. J Clin Psychiatry. 2008;69(Suppl E1):4-7.

6. Kasper S, Pail G. Milnacipran: a unique antidepressant? Neuropsychiatr Dis Treat. 2010;6:23-31.

7. Carlsson A, Corrodi H, Fuxe K, Hökfelt T. Effect of antidepressant drugs on the depletion of intraneuronal brain 5-hydroxytryptamine stores caused by 4-methyl-alpha-ethyl-meta-tyramine. Eur J Pharmacol. 1969;5:357-366.

8. Healy D, McMonagle T. The enhancement of social functioning as a therapeutic principle in the management of depression. J Psychopharmacol. 1997;11(Suppl 4):S25-S31.

9. Katon W. The impact of depression on workplace functioning and disability costs. Am J Manag Care. 2009;15(Suppl 11):S322-S327.

10. Weissman MM, Klerman GL, Paykel ES, et al. Treatment effects on the social adjustment of depressed patients. Arch Gen Psychiatry. 1974;30:771-778.

11. Paykel ES, Weissman MM, Prusoff BA. Social maladjustment and severity of depression. Compr Psychiatry. 1978;19:121-128.

12. Hays RD, Wells KB, Sherbourne CD, et al. Functioning and well-being outcomes of patients with depression compared with chronic general medical illnesses. Arch Gen Psychiatry. 1995;52:11-19.

13. Leader JB, Klein DN. Social adjustment in dysthymia, double depression and episodic major depression. J Affect Disord. 1996;37:91-101.

14. Tse WS, Bond AJ. The impact of depression on social skills. J Nerv Ment Dis. 2004;192:260-268.

15. Bech P. Social functioning: should it become an endpoint in trials of antidepressants? CNS Drugs. 2005;19:313-324.

16. Daly EJ, Trivedi MH, Wisniewski SR, et al. Health-related quality of life in depression: a STAR*D report. Ann Clin Psychiatry. 2010;22: 43-55.

17. Weissman MM, Olfson M, Gameroff MJ, et al. A comparison of three scales for assessing social functioning in primary care. Am J Psychiatry. 2001;158:460-466.

18. Bosc M, Dubini A, Polin V. Development and validation of a social functioning scale, the Social Adaptation Self-evaluation Scale. Eur Neuropsychopharmacol. 1997;7(Suppl 1):S57-S70.

19. Bosc M. Assessment of social functioning in depression. Compr Psychiatry. 2000;41:63-69.

20. Healy D. Reboxetine: its effects as measured by the Social Adaptation Self-evaluation Scale. Acta Psychiatr Scand. 2000;402(Suppl): $45-51$.

21. Ware JE Jr, Sherbourne CD. The MOS 36-item Short-Form Health Survey (SF-36). I. Conceptual framework and item selection. Med Care. 1992;30:473-483.

22. Tse WS, Bond AJ. Difference in serotonergic and noradrenergic regulation of human social behaviours. Psychopharmacology (Berl). 2002;159:216-221.
22. Weissman MM, Bothwell S. Assessment of social adjustment by patient self-report. Arch Gen Psychiatry. 1976;33:1111-1115.

23. Tse WS, Bond AJ. Reboxetine promotes social bonding in healthy volunteers. J Psychopharmacol. 2003;17:189-195.

24. Tse WS, Bond AJ. Noradrenaline might enhance assertive human social behaviours: an investigation in a flatmate relationship. Pharmacopsychiatry. 2006;39:175-179.

25. Paykel ES, Weissman MM. Social adjustment and depression. A longitudinal study. Arch Gen Psychiatry. 1973;28:659-663.

26. Dubini A, Bosc M, Polin V. Do noradrenaline and serotonin differentially affect social motivation and behaviour? Eur Neuropsychopharmacol. 1997;7(Suppl 1):S49-S55.

27. Dubini A, Bosc M, Polin V. Noradrenaline-selective versus serotonin-selective antidepressant therapy: differential effects on social functioning. J Psychopharmacol. 1997;11(Suppl 4): S17-S23

28. Massana J, Möller HJ, Burrows GD, Montenegro RM. Reboxetine: a double-blind comparison with fluoxetine in major depressive disorder. Int Clin Psychopharmacol. 1999;14:73-80.

29. Keller M. Role of serotonin and noradrenaline in social dysfunction: a review of data on reboxetine and the Social Adaptation Self-evaluation Scale (SASS). Gen Hosp Psychiatry. 2001;23:15-19.

30. Gorenstein C, Andrade L, Moreno RA, Artes R. Social adjustment in depressed patients treated with venlafaxine and amitriptyline. Int Clin Psychopharmacol. 2002;17:171-175.

31. Mbaya P. Safety and efficacy of high dose of venlafaxine XL in treatment resistant major depression. Hum Psychopharmacol. 2002;17: 335-339.

32. Pjrek E, Willeit M, Praschak-Rieder N, et al. Treatment of seasonal affective disorder with duloxetine: an open-label study. Pharmacopsychiatry. 2008:41:100-105.

33. Koch S, Hemrick-Luecke SK, Thompson LK, et al. Comparison of effects of dual transporter inhibitors on monoamine transporters and extracellular levels in rats. Neuropharmacology. 2003;45: 935-944.

34. Stahl SM, Grady MM, Moret C, Briley M. SNRIs: their pharmacology, clinical efficacy, and tolerability in comparison with other classes of antidepressants. CNS Spectr. 2005;10:732-747.

35. Yoshida K, Takahashi H, Higuchi H, et al. Prediction of antidepressant response to milnacipran by norepinephrine transporter gene polymorphisms. Am J Psychiatry. 2004;161:1575-1580.

36. Hindmarch I. Psychomotor function and psychoactive drugs. Br J Clin Pharmacol. 1980;10:189-209.

37. Hindmarch I, Rigney U, Stanley N, Briley M. Pharmacodynamics of milnacipran in young and elderly volunteers. $\mathrm{Br} J$ Clin Pharmacol. 2000;49:118-125.

38. Sechter D, Vandel P, Weiller E, et al. A comparative study of milnacipran and paroxetine in outpatients with major depression. $J$ Affect Disord. 2004;83:233-236.

39. Puech A, Montgomery SA, Prost JF, et al. Milnacipran, a new serotonin and noradrenaline reuptake inhibitor: an overview of its antidepressant activity and clinical tolerability. Int Clin Psychopharmacol. 1997;12: 99-108.

40. Kasper $\mathrm{S}$. The place of milnacipran in the treatment of depression. Hum Psychopharmacol. 1997;12:S135-S141.

41. Fukuchi T, Kanemoto K. Differential effects of milnacipran and fluvoxamine, especially in patients with severe depression and agitated depression: a case-control study. Int Clin Psychopharmacol. 2002;17: $53-58$.

42. Lemoine P, Faivre T. Subjective and polysomnographic effects of milnacipran on sleep in depressed patients. Hum Psychopharmacol. 2004;19:299-303.

43. Briley M, Moret C. Improvement of social adaptation in depression with serotonin and norepinephrine reuptake inhibitors. Neuropsychiatr Dis Treat. 2010;6:647-655. 
44. Ueda N, Yoshimura R, Houjo T, et al. Effects of milnacipran on social adaptation in patients with depression. Rinshyo Seisin Yakuri. 2008;11: 273-279.
45. Ishida T, Inada Y, Kudo M, et al. Study on the clinical efficacy of milnacipran by using the Social Adaptation Self-evaluation Scale. Jap J Clin Psychopharmacol. 2010;13:77-83.

\section{Publish your work in this journal}

Neuropsychiatric Disease and Treatment is an international, peerreviewed journal of clinical therapeutics and pharmacology focusing on concise rapid reporting of clinical or pre-clinical studies on a range of neuropsychiatric and neurological disorders. This journal is indexed on PubMed Central, the 'PsycINFO' database and CAS, and is the official journal of The International Neuropsychiatric Association (INA). The manuscript management system is completely online and includes a very quick and fair peer-review system, which is all easy to use. Visit http://www.dovepress.com/testimonials.php to read real quotes from published authors.

Submit your manuscript here: http://www.dovepress.com/neuropsychiatric-disease-and-treatment-journal 